\title{
Total Synthesis of (+)-Scholarisine A
}

\author{
Gregory L. Adams, Patrick J. Carroll, and Amos B. Smith III* \\ Department of Chemistry, Laboratory for Research on the Structure of Matter, and Monell \\ Chemical Senses Center, University of Pennsylvania, Philadelphia, Pennsylvania 19104
}

\begin{abstract}
An effective total synthesis and assignment of the absolute configuration of the architecturally challenging (+)-scholarisine A has been achieved via a 20-step sequence. Highlights include a reductive cyclization, involving a nitrile and an epoxide; a modified Fischer indole protocol; a late stage oxidative-lactonization; and an intramolecular cyclization leading to the indolenine ring system of (+)-scholarisine A.
\end{abstract}

Scholarisine A (1), a monoterpenoid indole alkaloid first isolated in 2008 from the leaves of Alstonia scholaris, comprises an unprecedented scaffold containing a bridged lactone inscribed in a cage-like skeleton (Figure 1). ${ }^{1}$ Although no information on the bioactivity of scholarisine A (1) is currently available, congeners of a putative biosynthetic precursor, picraline (3), ${ }^{2}$ have been reported to be potent, selective inhibitors of SGLT2, a renal cortex membrane protein that regulates glucose re-absorption, that was recently validated as a target for type II diabetes intervention. ${ }^{3}$

Alkaloids that derive biosynthetically from geissoschizine (5), via a cyclization leading to a bond between C-7 and C- $16^{4}$ are classified as the akuammiline alkaloids (Figure 1), ${ }^{5}$ named after akuammiline (7), ${ }^{6}$ first characterized in $1932 .{ }^{7}$ Loss of the acetoxymethyl moiety leads to strictamine (6). ${ }^{8}$ Hydrolysis and further functionalization is envisioned to provide alkaloids with a furoindoline core such as aspidodasycarpine $(\mathbf{8})^{9}$ and aspidophylline A (9), ${ }^{10}$ the latter the target of a recent elegant racemic total synthesis by Garg. ${ }^{11}$ Alternatively akuammiline (7) could give rise to picrinine $(4)^{12}$ upon loss of the acetoxymethyl moiety from C-16 and oxidation at C-5. Scholarisine A (1), the target of this study, is proposed to arise from picrinine (4) via initial opening of the oxygen bridge at $\mathrm{C}-2$ via participation of the indoline nitrogen and cleavage of the N-4 to C-5 bond to furnish an aldehyde at C-5; migration of the double bond, nucleophilic attack by the resulting enamine carbon, and capture of the resulting hydroxyl group by the methyl ester would lead to the lactone ring of scholarisine A (1). ${ }^{1}$

Given the novel architectural features of scholarisine A (1), in conjunction with the inherent synthetic challenge and the possibility of discovering a substrate that would permit a novel enantioselective route to the currently unobtainable akuammiline alkaloids via a late stage "retro-biosynthetic" fragmentation, ${ }^{13}$ we initiated a synthetic program to construct scholarisine A (1) in 2008. We report here the first total synthesis of (+)-scholarisine A (1), comprising an enantiospecific strategy.

*Corresponding author: smithab@sas.upenn.edu.

ASSOCIATED CONTENT

Supporting Information. Experimental details, spectra, and X-ray crystallography. This material is available free of charge via the Internet at http://pubs.acs.org. 
From the retrosynthetic perspective, we envisioned scholarisine A (1) to arise via cyclization and oxidation of indole lactone $\mathbf{1 0}$ (Figure 2). Construction of the latter would entail an oxidative-lactonization of diol 11 with subsequent deprotection. Diol 11 in turn could derive from lactone 12, via homologation and reduction, the latter obtained from tricyclic amine 13, upon amine protection, oxidation and a Fischer indole annulation. Amine 13, the cornerstone construct of this synthetic venture was envisioned to be the product of a reductive-cyclization involving the nitrile and epoxide functionalities present in lactone $\mathbf{1 4}$, which could be prepared from known bicyclic lactone (-)-15. ${ }^{14}$

Towards this end, cyanation of (-)-15 with cyanobenzotrizole (Scheme 1), using basic conditions, ${ }^{15}$ provided nitrile lactone $(+)-16^{16}$ in a $60 \%$ yield after an extractive workup. Alkylation occurring from the convex face utilizing ethyl iodide furnished cyanolactone $(-)-17^{16}$ in a $71 \%$ yield, which upon epoxidation with $m$ CPBA in chloroform, led to a mixture of epoxides. ${ }^{17}$ The desired epoxide (-)-14 ${ }^{16}$ was formed selectively over the undesired $(-)-\mathbf{1 8} ;{ }^{16}$ the ratio was $3: 1$. Crystallization from toluene provided pure (-)-14 in a $58 \%$ yield.

Reductive cyclization of epoxide (-)-14 was then achieved employing rhodium on alumina, ${ }^{18}$ via hydrogenation with in situ epoxide ring opening to generate tricylic compound (-)-13 ${ }^{16}$ (Scheme 2). Benzoyl protection of the amine in tricycle (-)-13, followed by oxidation of the hydroxyl group with $\mathrm{DMP}^{19}$ then led to ketone (+)-19. ${ }^{16}$

Turning to installation of the indole ring, ${ }^{20}$ a Fischer synthesis utilizing benzyl phenylhydrazine (pyridine- $\left.\mathrm{HCl}, 110^{\circ} \mathrm{C}\right)^{21}$ furnished the protected indole lactone (-)-12. We found that benzyl phenylhydrazine proved highly effective, whereas use of phenyl hydrazine led to complete decomposition. ${ }^{22}$ Indole (-)-12 was next reduced with $\mathrm{LiAlH}_{4}$ to furnish diol (+)-20, ${ }^{16}$ which co-crystallized with chloroform, permitting confirmation of the absolute configuration by X-ray analysis. Diol (+)-20 was next selectively protected as the TBDPS ether (+)-21, ${ }^{23}$ and in turn oxidized with tetrapropylammonium perruthenate using $\mathrm{N}$-methylmorpholine $\mathrm{N}$-oxide as a co-oxidant (TPAP/NMO) ${ }^{24}$ to furnish aldehyde (+)-22. Pleasingly, this 4-step sequence proved highly effective, proceeding in a 55\% yield. Earlier studies had indicated that protection of both nitrogen atoms was required to prevent side reactions during the oxidation process.

With aldehyde (+)-22 in hand, treatment with benzyloxymethyl lithium, derived from benzyloxymethyl tributylstannane and $n$-BuLi, ${ }^{25}$ led to diol (+)-11 as the major product after workup with methanolic $\mathrm{KOH}$ to remove the TBDPS group; this one-pot, two-step sequence proceeded in $63 \%$ yield. Studies involving NOESY NMR suggest the average conformation of the carbonyl in (+)-22 as illustrated in Figure 3. External electrophilic attack of (+)-22 would explain the high selectivity observed during the formation of diol (+)-11.

A two-step oxidative lactonization employing 2-iodoxybenzoic acid (IBX) in THF and DMSO (1:1), followed by TPAP/NMO in methylene chloride was next achieved to access lactone (-)-23 from diol (+)-11 in a 57\% yield. Stepwise oxidation to generate the lactol employing IBX ${ }^{26}$ prevents formation of the undesired side products that were observed when diol (+)-11 was subjected directly to the TPAP/NMO conditions. Subsequent treatment of lactone (-)-23 with $\mathrm{AlCl}_{3}$ in toluene under sonication conditions then selectively removed the protecting groups on the oxygen and indole nitrogen to furnish alcohol (-)-24 in an $83 \%$ yield. ${ }^{27}$

Various attempts to activate the hydroxyl group in (-)-24 for cyclization with the indole ring resulted in decomposition, most likely due to intramolecular cyclization involving the basic tertiary amine. Exchange of nitrogen protection was therefore required to attenuate the reactivity of the piperidine nitrogen. The latter was achieved via transfer hydrogenolysis to 
give amine (+)-10, ${ }^{16}$ followed by treatment with trifluoroacetylimidazole in $\mathrm{THF}^{28}$ to furnish trifluoroacetamide (-)-25 (Scheme 3). Activation of the $1^{\circ}$ alcohol with methanesulfonyl chloride then provided the stable sulfonate ester (-)-26, which upon cyclization triggered by indole deprotonation with tert-butylimino-tri(pyrrolidino)phosphorane $(\mathrm{BTPP})^{29}$ furnished indolenine (+)-27 in a $40 \%$ yield over 4 steps. Removal of the trifluoroacetyl group in (+)-27 with a mixture of saturated aqueous $\mathrm{K}_{2} \mathrm{CO}_{3}$ and methanol (1:2), followed by aliphatic amine oxidation with iodosobenzene (PHIO) in methylene chloride ${ }^{30}$ completed the synthesis of (+)-scholarisine A (1) ${ }^{16}$ which displayed spectral properties identical in all respects with those reported for the natural product [i.e., ${ }^{1} \mathrm{H}$ and ${ }^{13} \mathrm{C}$ NMR (500 and $125 \mathrm{MHz}$, respectively), HRMS parent ion identification, and chiroptic properties]. ${ }^{1}$

In summary, the first total synthesis and assignment of the absolute configuration of (+)scholarisine $\mathrm{A}$ has been achieved with a longest linear reaction sequence of 20 steps from known lactone (-)-15. ${ }^{31}$ Highlights of the synthesis include a reductive cyclization, involving a nitrile and an epoxide; a modified Fischer indole protocol; a late stage oxidativelactonization; and an intramolecular cyclization leading to the indolenine ring system of (+)scholarisine A.

\section{Supplementary Material}

Refer to Web version on PubMed Central for supplementary material.

\section{Acknowledgments}

Financial support was provided by the National Institute of Health (National Cancer Institute) through CA-19033. We also thank Drs. George Furst and Rakesh Kohli for help respectively obtaining the high resolution NMR and mass spectral data.

\section{References}

1. Cai XH, Tan QG, Liu YP, Feng T, Du ZZ, Li WQ, Luo XD. Org Lett. 2008; 10:577-580. [PubMed: 18205369]

2. (a) Britten AZ, Smith GF. J Chem Soc. 1963:3850-3854.(b) Britten A, Smith G, Spiteller G. Chem Ind. 1963:1492-1493.

3. (a) Arai H, Hirasawa Y, Rahman A, Kusumawati I, Zaini NC, Sato S, Aoyama C, Takeo J, Morita H. Bioorg Med Chem. 2010; 18:2152-2158. [PubMed: 20189404] (b) Meng W, Ellsworth BA, Nirschl AA, McCann PJ, Patel M, Girotra RN, Wu G, Sher PM, Morrison EP, Biller SA, Zahler R, Deshpande PP, Pullockaran A, Hagan DL, Morgan N, Taylor JR, Obermeier MT, Humphreys WG, Khanna A, Discenza L, Robertson JG, Wang A, Han S, Wetterau JR, Janovitz EB, Flint OP, Whaley JM, Washburn WN. J Med Chem. 2008; 51:1145-1149. [PubMed: 18260618]

4. (a) Smith GF. Chem Ind. 1961:1120.(b) Wenkert E, Wickberg B. J Am Chem Soc. 1965; 87:15801589. [PubMed: 14306194]

5. (a) Ramirez A, Garcia-Rubio S. Curr Med Chem. 2003; 10:1891-1915. [PubMed: 12871110] (b) Llopart CC, Joule JA. Arkivoc. 2004; x:20-38.

6. Olivier L, Levy J, Le Men J, Janot MM, Budzikiewicz H, Djerassi C. Bull Soc Chim Fr. 1965:868876.

7. Henry TA. J Chem Soc. 1932:2759-2768.

8. (a) Schnoes H, Biemann K, Mokry J, Kompis I, Chatterjee A, Ganguli G. J Org Chem. 1966; 31:1641-1642.(b) Ahmad Y, Fatima K, Rahman A, Occolowitz J, Solheim B, Clardy J, Garnick R, Le Quesne P. J Am Chem Soc. 1977; 99:1943-1946.

9. (a) Joule JA, Ohashi M, Gilbert B, Djerassi C. Tetrahedron. 1965; 21:1717-1734. [PubMed: 5879390] (b) Ohashi M, Joule JA, Djerassi C. Tetrahedron Lett. 1964; 51:3899-3905. 
10. Subramaniam G, Hiraku O, Hayashi M, Koyano T, Komiyama K, Kam TS. J Nat Prod. 2007; 70:1783-1789. [PubMed: 17939738]

11. Zu L, Boal BW, Garg NK. J Am Chem Soc. 2011; 133:8877-8879. [PubMed: 21553860]

12. (a) Chatterjee A, Mukherjee B, Ray AB, Das B. Tetrahedron Lett. 1965; 41:3633-3637. [PubMed: 5842459] (b) Ghosh R, Roychowdhury P, Chattopadhyay D, Iitaka Y. Acta Crystallogr, Sect C: Cryst Struct Commun. 1988; 44:2151-2154.

13. Oxidation state manipulation and/or functionalization would most likely be required for such a fragmentation. Indoline 28, a reported degradation derivative of aspidodasycarpine (see ref. 9), possesses the carbon scaffold contained in the akuammiline alkaloids. All members of this class can be considered as oxidized and functionalized analogs of this scaffold.

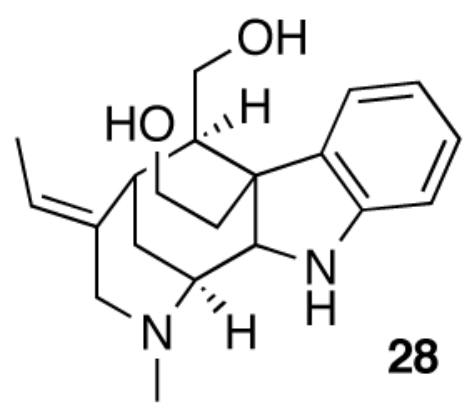

14. The synthesis of lactone (-)-15 was prepared via the reported 4-step enzyme-mediated asymmetrization and functionalization of meso-cyclohex-4-ene-1,2-dimethanol. (a) Danieli B, Lesma G, Mauro M, Palmisano G, Passarella D. J Org Chem. 1995; 60:2506-2513.(b) Danieli B, Lesma G, Mauro M, Palmisano G, Passarella D. Tetrahedron. 1994; 50:8837-8852.(c) Danieli B, Lesma G, Mauro M, Palmisano G, Passarella D. Tetrahedron: Asymmetry. 1990; 1:793-800.See the supporting information for a modified preparation, amenable to scale up.

15. (a) Hughes TV, Hammond SD, Cava MP. J Org Chem. 1998; 63:401-402.(b) Katritzky AR, AkueGedu R, Vakulenko AV. Arkivoc. 2007; iii:5-12.(c) Katritzky AR, Brzezinski JZ, Lam JN. Rev Roum Chim. 1991; 36:573-580.

16. The structures of $(+)-\mathbf{1 0},(-)-\mathbf{1 3},(-)-\mathbf{1 4},(+)-\mathbf{1 6},(-)-\mathbf{1 7},(-)-\mathbf{1 8},(+)-\mathbf{1 9},(+)-\mathbf{2 0}$, and totally synthetic scholarisine A (1) were confirmed by single crystal X-ray analysis.

17. (a) Kasai T, Watanabe H, Mori K. Bioorg Med Chem. 1993; 1:67-70. [PubMed: 8081839] (b) OBrien P, Tournayre J. Tetrahedron. 1997; 53:17527-17542.

18. To our knowledge this is the first example of such a cyclization. (a) Rhodium on alumina has been shown to tolerate the oxirane moiety: Tarbell DS, West RL, McNally JG, McCorkindale NJ, Kunstmann M, Carman RM, Cremer SE, Cross AD, Huffman KR, Varino HL, Rosowsky A, Chapman DD. J Am Chem Soc. 1961; 83:3096-3113. Rhodium on alumina has also been shown to reduce nitriles preferentially to primary amines: (b) Freifelder M. J Am Chem Soc. 1960; 82:2386-2389. Bridged azapolycyclic alcohols have been synthesized via intramolecular expoxide opening by an amide: (c) Schultz R, Staas W, Spurlock L. J Org Chem. 1973; 38:3091-3093.

19. Dess DB, Martin JC. J Org Chem. 1983; 48:4155-4156.

20. Our approach to the akuammiline type alkaloids exploiting a Fischer indole synthesis with the 2azabicyclo [3.3.1]nonan-8-one ring system was inspired by Dolby's pioneering efforts: see (a) Dolby LJ, Esfandiari Z. J Org Chem. 1972; 37:43-46. [PubMed: 5007281] (b) Dolby LJ, Nelson SJ. J Org Chem. 1973; 38:2882-2887. [PubMed: 4733444] Garg has also recently used this approach; see ref 11. We also note the work of Bosch: see (c) Bennasar ML, Zulaica E, Lopez M, 
Bosch J. Tetrahedron Lett. 1988; 29:2361-2364.(d) Bosch J, Bennasar ML. Synlett. 1995:587596.(e) Bennasar ML, Zulaica E, Ramirez A, Bosch J. J Org Chem. 1996; 61:1239-1251.

21. (a) Welch WM. Synthesis. 1977:645-646.(b) Perni RB, Gribble GW. Org Prep Proced Int. 1982; 14:343-346.

22. Benzoylphenylhydrazine also provided a stable hydrazone intermediate, but lead to the unprotected indole upon cyclization. See: Mills K, Alkhawaja K, Alsaleh F, Joule JA. J Chem Soc, Perkin Trans 1 (1972-1999). 1981:636-641.

23. Hanessian S, Lavallee P. Can J Chem. 1975; 53:2975-2977.

24. Ley SV, Norman J, Griffith WP, Marsden SP. Synthesis. 1994:639-666.

25. Still WC. J Am Chem Soc. 1978; 100:1481-1487.

26. (a) Corey E, Palani A. Tetrahedron Lett. 1995; 36:7945-7948.(b) Corey E, Palani A. Tetrahedron Lett. 1995; 36:3485-3488.

27. (a) Watanabe T, Kobayashi A, Nishiura M, Takahashi H, Usui T, Kamiyama I, Mochizuki N, Noritake K, Yokoyama Y, Murakami Y. Chem Pharm Bull. 1991; 39:1152-1156.(b) Murakami Y, Watanabe T, Kobayashi A, Yokoyama Y. Synthesis. 1984:738-740.

28. Staab H, Walther G. Chem Ber. 1962; 95:2070-2072.

29. Schwesinger R, Willaredt J, Schlemper H, Keller M, Schmitt D, Fritz H. Chem Ber. 1994; 127:2435-2454.

30. (a) Muller P, Gilabert D. Tetrahedron. 1988; 44:7171-7175.(b) Larsen J, Jorgensen K. J Chem Soc, Perkin Trans 2 (1972-1999). 1992:1213-1217.

31. Assignment of the absolute configuration of (+)-scholarisine A (1) derives from the known absolute configurations of (-)-15 and (+)-20. 

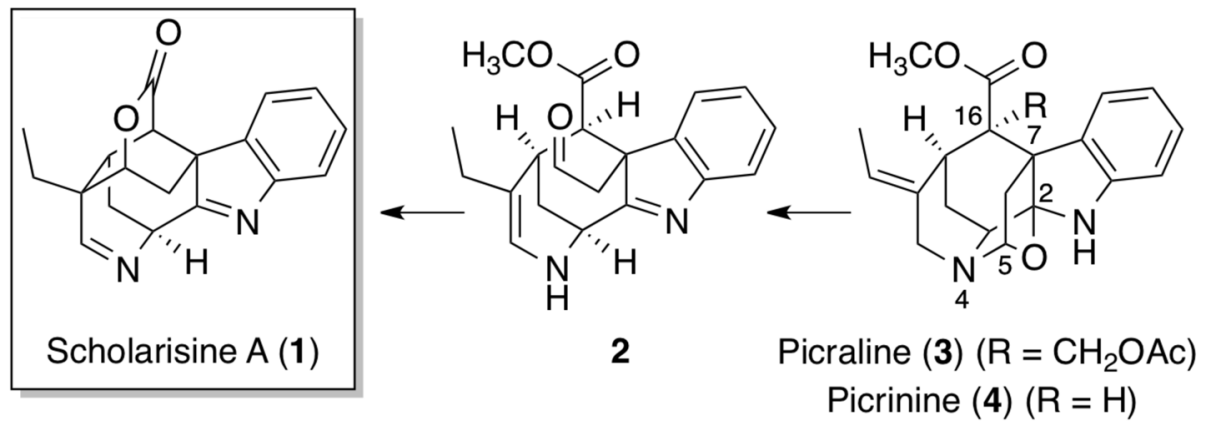<smiles>C/C=C1/CN2[13CH2]C[C@@H]3c4[nH]c5ccccc5c4[C@H]3[C@H]2C[C@@H]1/C(=C/O)C(=O)OC</smiles>

Geissoschizine (5)

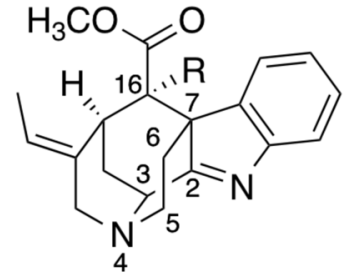

Strictamine (6) $(\mathrm{R}=\mathrm{H})$

Akuammiline (7)

$\left(\mathrm{R}=\mathrm{CH}_{2} \mathrm{OAc}\right)$

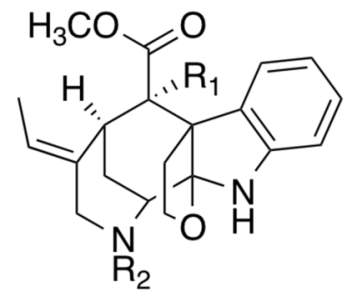

Aspidodasycarpine (8) $\left(\mathrm{R}^{1}=\mathrm{CH}_{2} \mathrm{OH}, \mathrm{R}^{2}=\mathrm{H}\right)$ Aspidophylline $\mathrm{A}(\mathbf{9})$ $\left(\mathrm{R}^{1}=\mathrm{H}, \mathrm{R}^{2}=\mathrm{CHO}\right)$

Figure 1.

Biosynthesis of (+)-scholarisine A (1). 


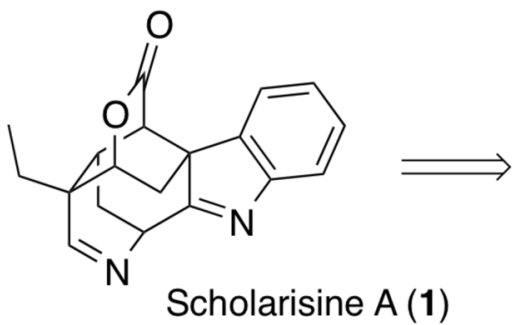

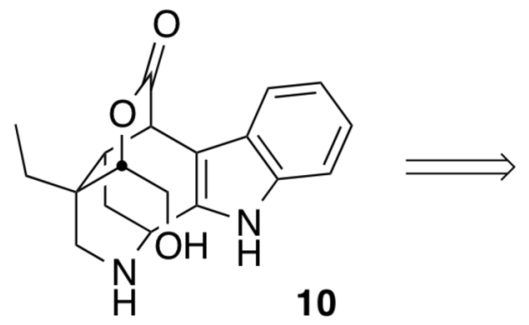<smiles>CCC12CN(Br)CC(CO)(CN(Br)C1)C2c1[nH]c2ccccc2c1O</smiles><smiles>C=CCC1CNC(=O)c2c1c1ccccc1n2CCOC(=O)c1ccccc1</smiles>

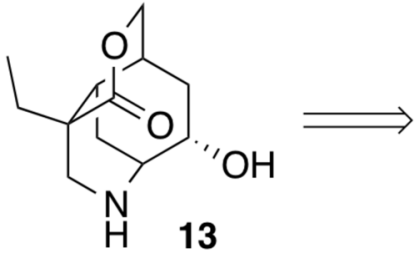<smiles>CC[C@]1(C#N)C(=O)OC[C@H]2C[C@@H]3O[C@H]3C[C@H]21</smiles><smiles>C=CC</smiles><smiles>O=C1C[C@H]2CC=CC[C@H]2CO1</smiles>

Figure 2.

Retrosynthetic analysis of (+)-scholarisine A (1). 


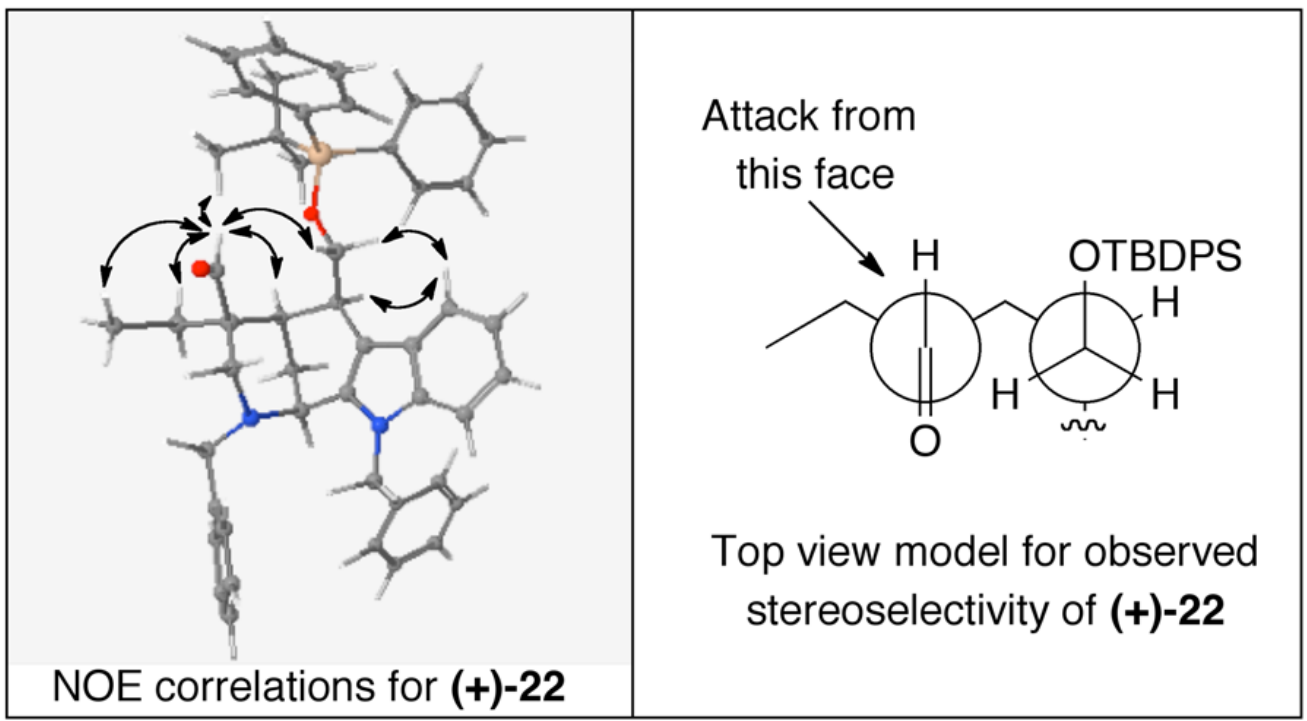

Figure 3. 


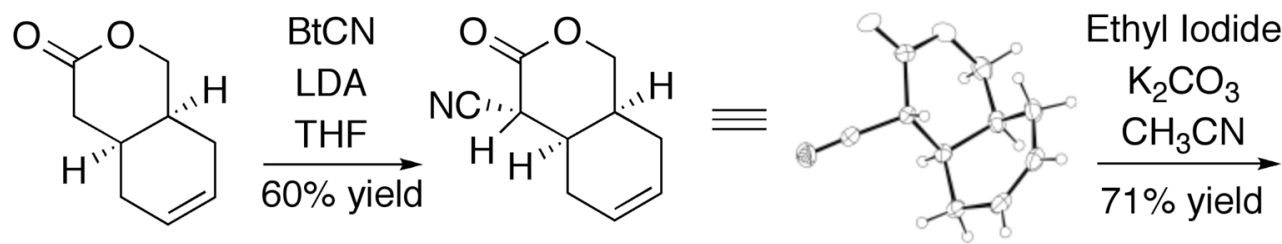

$(-)-15$

(+)-16

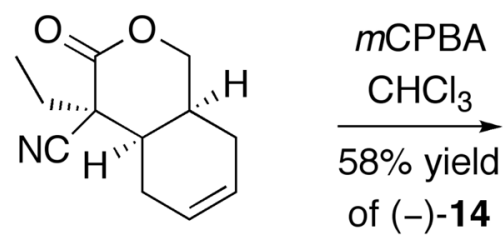<smiles>CC[C@]1(C#N)C(=O)OC[C@H]2C[C@@H]3O[C@@H]3C[C@H]21</smiles><smiles>CC[C@@]1(C#N)C(=O)OC[C@H]2C[C@@H]3O[C@H]3C[C@H]21</smiles><smiles></smiles><smiles>[124IH]</smiles><smiles>[3H][131I]=[W]</smiles>

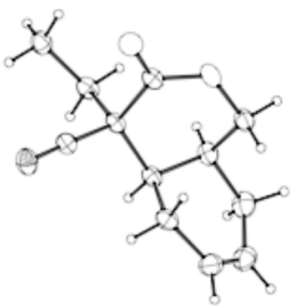

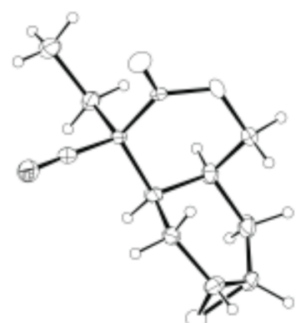

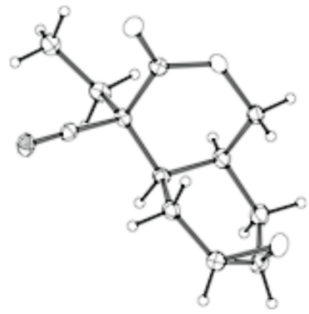

Scheme 1. 

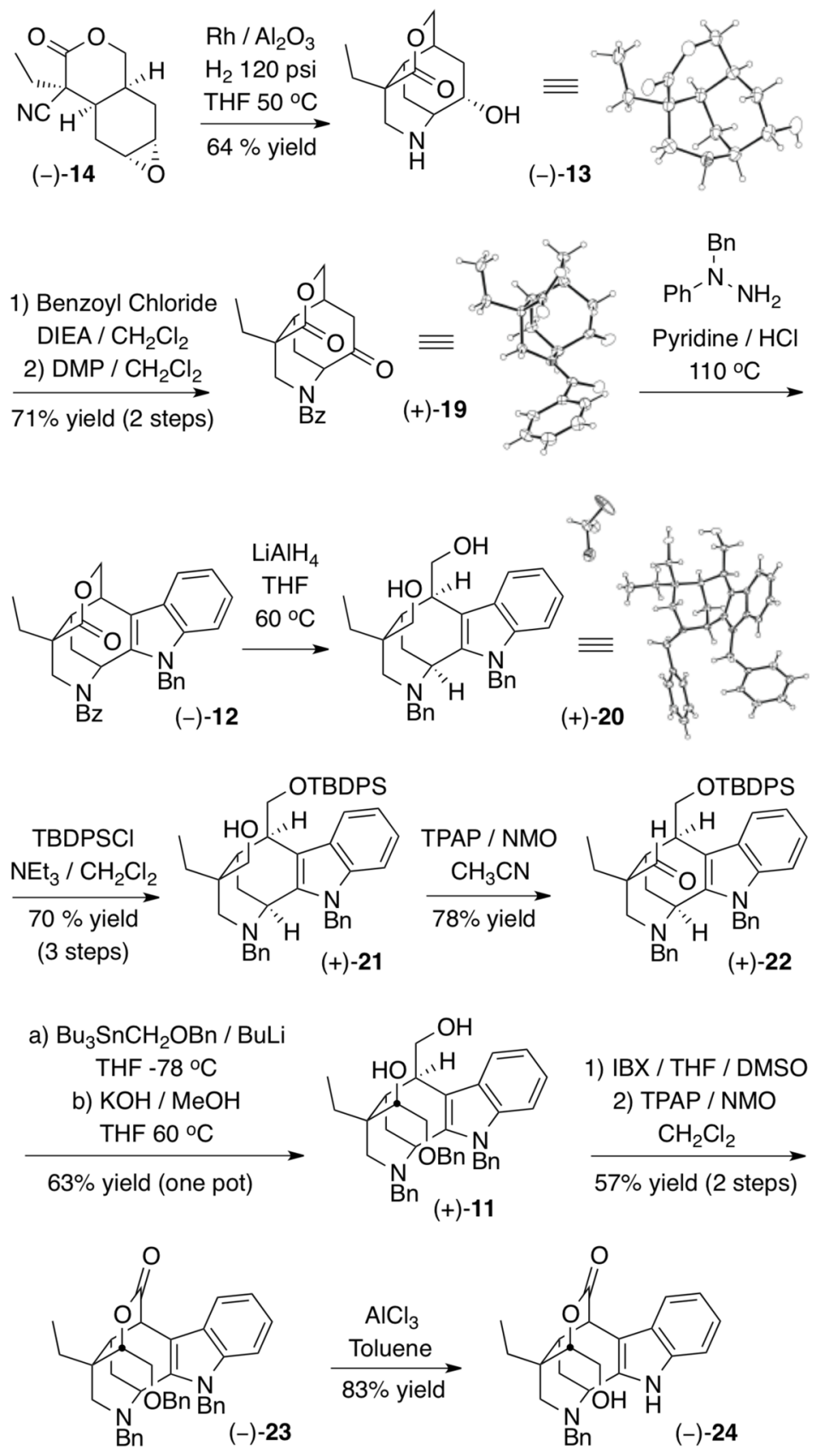

Scheme 2. 


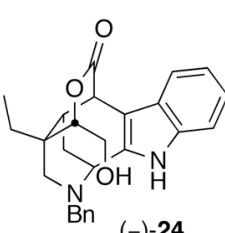

$\mathrm{Pd}(\mathrm{OH})_{2} / \mathrm{C}$ $\mathrm{NH}_{4} \mathrm{HCO}_{2}$

Methanol

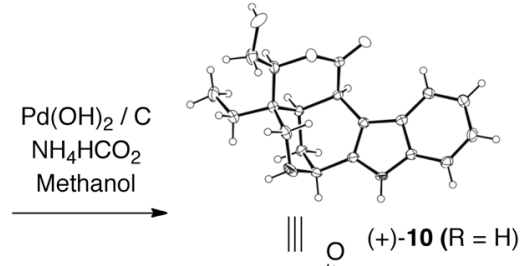

$(-)-24$
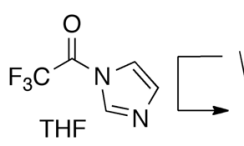<smiles>CC1CC2CC=COC(CC2)C1</smiles><smiles>C1C2C3C4C1C1C2C3C41</smiles>

$\mathrm{NOH}$

$(-)-25\left(R=\mathrm{COCF}_{3}\right)$
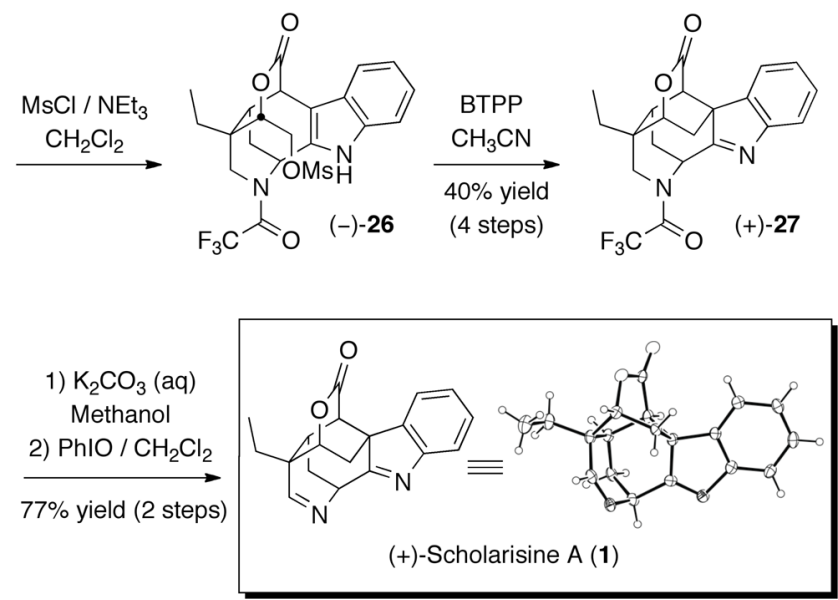

Scheme 3. 